\title{
Covid-19 em Santa Catarina: um triste experimento populacional ${ }^{*}$
}

\author{
Covid-19 in Santa Catarina: \\ a sad population experiment
}

\author{
Sandra Caponi ${ }^{i}$ \\ i Professora, Departamento de \\ Sociologia e Ciências Políticas/ \\ Universidade Federal de Santa \\ Catarina. \\ Florianópolis - SC - Brasil \\ orcid.org/0000-0001-8180-944X \\ sandracaponi@gmail.com
}

Recebido em 30 ago. 2020. Aprovado em 13 set. 2020.
CAPONI, Sandra. Covid-19 em Santa Catarina: um triste experimento populacional. História, Ciências, Saúde - Manguinhos, Rio de Janeiro, v.28, n.2, abr.-jun. 2021, p.593-598.

\section{Resumo}

As dificuldades existentes com o enfrentamento da pandemia em Santa Catarina seguem a mesma trajetória dramática do Brasil, com número crescente de casos e mortes diárias. O estado conta com várias regiões consideradas em risco gravíssimo ou grave. A gestão inicialmente bemsucedida da pandemia, referenciada como um modelo a ser seguido, pouco a pouco foi perdendo coerência e efetividade, cedendo a pressões advindas de poderes políticos e econômicos, em especial de grandes empresários do estado.

Palavras-chave: covid-19; Santa Catarina; necropolítica; história.

\section{Abstract \\ Difficulties related to the coronavirus pandemic in the state of Santa Catarina reflect the same dramatic trajectory seen in Brazil as a whole, with increasing numbers of cases and daily fatalities. Several regions of this state are considered to be at very serious or severe risk. The initially successful management of the pandemic was cited as a model to be followed, but gradually lost coherence and effectiveness as it yielded to pressure from political and economic powers, particularly large employers in the state.}

Keywords: covid-19; Santa Catarina (state); necropolitics; history. 
$\mathrm{N}_{\mathrm{a}}^{\circ}$ o dia 9 de setembro, o Brasil superou 128 mil mortos por covid-19. Todos sabíamos que chegaríamos a esse número trágico, assim como todos sabemos que os números de mortes continuarão aumentando, pois as medidas tomadas até hoje pelo governo federal não foram eficazes para diminuir e controlar a pandemia.

A situação em Santa Catarina segue a mesma trajetória dramática do Brasil, com número crescente de casos e mortes diárias. No boletim divulgado pelo Governo do Estado de Santa Catarina no dia 8 de setembro foram registrados 192.982 casos e 2.460 mortes, com um índice de distanciamento social baixo, de 34,4\% (Governo do Estado de Santa Catarina, 8 set. 2020). Em 9 de setembro, a maior parte das 16 regiões do estado encontrava-se em nível de risco grave, e duas regiões do norte do estado, em risco gravíssimo. Parece significativo que no mesmo dia (8 de setembro) em que a Folha de S.Paulo divulgou que Santa Catarina era um dos estados que apresentavam aumento acelerado de casos, os jornais catarinenses destacavam, como sendo um sucesso, o elevado número de pessoas recuperadas. Desconsideravam que o número de recuperados aumentou simplesmente porque o número de contágios era muito elevado. Essa divulgação se dá no marco de uma grande euforia geral, pois, pouco a pouco, Santa Catarina começava a se organizar para abrir a temporada de turismo e receber visitantes. Mesmo com as mortes multiplicando-se, no dia 23 de agosto, quando a capital do estado contava 5.200 casos registrados e 105 óbitos, em uma curva claramente ascendente, o secretário de Saúde afirmou que Florianópolis é um dos destinos mais procurados pelos turistas, o que seria resultado do bom trabalho realizado no enfrentamento à covid-19. "Estamos passando uma sensação de segurança muito grande. Todo o trabalho foi desenvolvido para que as pessoas tenham segurança em vir para aqui" (Gadotti, 23 ago. 2020).

Os meses de julho e agosto, porém, não foram calmos nem tranquilos no estado e não mostraram sucesso no enfrentamento da covid-19. O isolamento social praticamente deixou de existir, os comércios, shoppings, praias, restaurantes e bares estão funcionando de maneira praticamente normal, ainda que com alguns cuidados de distanciamento e uso de máscara. As medidas de distanciamento que ainda se mantêm são muito poucas: suspensão de aulas presenciais em todos os níveis educativos e suspensão de conferências públicas e eventos sociais, com a exceção de missas e cultos religiosos, que podem ser realizados mesmo nas regiões consideradas de risco gravíssimo. Sabemos desde o início da pandemia que essas medidas estão claramente vinculadas ao aumento de casos e de mortes por covid. Os dados em Santa Catarina em quase um mês de isolamento, de 17 de março até 13 de abril, quando foi autorizada a abertura do comércio de rua, indicavam 26 óbitos. Em quatro meses, com a flexibilização quase total do isolamento, chegamos ao dia 9 de setembro com 2.460 óbitos, um aumento de quase $1.000 \%$.

Para analisar como chegamos a uma situação tão dramática, devemos lembrar a história recente de gestão da pandemia. Inicialmente muito bem-sucedida e referenciada como um modelo a ser seguido, aos poucos foi perdendo coerência e efetividade, como resultado de pressões externas. Por um lado, essas pressões respondem aos interesses dos empresários locais alinhados ao governo nacional, que continuam lutando pelo fim do isolamento social. Por outro, é preciso lembrar que o governador do estado, Carlos Moisés, é filiado ao PSL, partido pelo qual o presidente Bolsonaro se elegeu. Sabemos que o presidente 
sempre se posicionou publicamente contra as medidas de isolamento e interrupção do comércio e da indústria. Como gestor dos recursos públicos destinados ao controle da pandemia nos estados, o posicionamento do presidente acaba exercendo pressão sob a forma como os governadores administram a pandemia. Cada visita do presidente ao estado foi acompanhada de aglomerações e carreatas de seus seguidores pedindo o fim do isolamento. Por fim, deve-se destacar a debilidade política do governador de Santa Catarina, atualmente alvo de um pedido de impeachment, sob a acusação de cometer crime de responsabilidade. Sua gestão também é questionada pelos $\mathrm{R} \$ 33$ milhões destinados à compra de respiradores de empresas-fantasma (Bispo, Potter, 28 abr. 2020). De acordo com o relatório da Comissão Parlamentar de Inquérito (CPI) dos respiradores do dia 18 de agosto, já foram comprovadas inúmeras irregularidades e fraudes nessa compra.

Esses fatos contribuíram para uma mudança radical de atitude do governo do estado perante a pandemia, abandonando as medidas exitosas que foram adotadas inicialmente. Assim, quando analisamos o desenvolvimento das estratégias de controle da epidemia que se sucederam em Santa Catarina, desde a aparição dos primeiros casos até hoje, parece que estamos diante de um triste experimento populacional sobre a eficácia da quarentena. Triste, porque as medidas de isolamento social adotadas muito rapidamente pelo governo do estado e pela prefeitura de Florianópolis, que a princípio se mostraram muito bem sucedidas e contaram com o compromisso da população, logo foram abandonadas em virtude das pressões relatadas.

No dia 3 de março, a Secretaria de Saúde do estado de Santa Catarina elaborou a primeira Nota Técnica a respeito da covid-19, sobre notificação, coleta e definição de orientações para casos suspeitos da doença (Governo de Santa Catarina, 2020). Alguns dias depois, em 17 de março, o governador do estado, Carlos Moisés (PSL), e o prefeito da cidade de Florianópolis, Gean Loureiro (DEM), decretaram situação de emergência no estado e no município, após a confirmação da existência de três casos de transmissão comunitária. Com a declaração de quarentena, foram suspensas diversas atividades, como a circulação de transporte urbano e intermunicipal, e atividades e serviços não essenciais, como academias, comércios, shoppings, hotéis e restaurantes. Também foram proibidas as reuniões de qualquer natureza, missas, cultos, festas, cursos, escolas etc.

No dia 14 de maio de 2020, o presidente declarou "estamos em guerra", não contra o vírus, mas contra os governadores que defendem as medidas de isolamento social. Nesse dia, Bolsonaro dirigiu-se diretamente aos empresários, para que impusessem obstáculos às medidas de isolamento adotadas nos diferentes estados, afirmando: "O lockdown é o caminho do fracasso, vai quebrar o Brasil. O caos se fará presente" (Kotscho, 14 maio 2020).

A ausência total de um Poder Executivo nacional capaz de investir maciçamente na conscientização dos riscos da pandemia e de garantir estratégias socioeconômicas de ajuda às populações vulneráveis acabou levando os esforços inicialmente realizados com a implantação da quarentena ao fracasso. Chegamos assim a assistir a um verdadeiro espetáculo de insensatez com a abertura de um shopping na cidade de Blumenau, que foi vista em todo Brasil. Como resultado, uma semana mais tarde, o número de casos praticamente duplicou no município, que se tornou, no dia 9 de setembro, uma das cidades do estado com maior número de óbitos (126), superando os 116 da capital. 
Santa Catarina compartilha com outros estados o grave problema da subnotificação. Pesquisa realizada na Universidade Federal de Santa Catarina (UFSC) em colaboração com a Univille e a Universidade de Waterloo (Canadá), denominada "Estimativa de subnotificação de casos de covid-19 no Estado de Santa Catarina", indica que o número de casos seria 28 vezes maior do que indicam os dados oficiais. Essa pesquisa destaca que estão sendo desconsiderados casos de síndrome respiratória aguda grave (SRAG), que aumentaram consideravelmente se comparados aos dados oficiais de anos anteriores (Nogueira et al., 2020).

Quando observamos como aumenta o número de mortes, constatamos que a situação parece estar fora de controle em Santa Catarina. Lamentavelmente, parece que o acúmulo de mortos não tem nenhum impacto real na mudança de políticas adotadas para enfrentar a pandemia, nem no estado, nem no Brasil.

Se a guerra declarada por Bolsonaro aos governadores e prefeitos no dia 14 de maio tinha como objetivo principal a flexibilização do isolamento social, ela parecia ter também um objetivo secundário, e solidário, ao primeiro. A liberação de um medicamento sem eficácia para tratamento de infecções causadas por covid-19 e com efeitos colaterais extremamente sérios, a cloroquina, que encontrou defensores radicais no estado de Santa Catarina.

De fato, o maior compromisso do estado parece estar na tentativa, muito pouco eficaz, de garantir a prevenção da covid-19 por via farmacológica. Ainda que o mundo inteiro saiba muito bem que não existe nenhum medicamento capaz de prevenir a infecção, vemos a insistente divulgação do uso preventivo da cloroquina, um medicamento sem nenhuma eficácia, mas com efeitos colaterais extremamente sérios (Berlivet, Lowy, 5 maio 2020). A insistência em uma cura miraculosa tem um efeito ideológico profundo. Pois, existindo uma "bala mágica" que permita um suposto tratamento eficaz, não haveria motivos para continuar mantendo a quarentena. No estado de Santa Catarina, parte da comunidade médica faz uma defesa explícita da cloroquina, para cuja fabricação o Brasil destinou R \$ 1,5 milhão, dinheiro suficiente para produzir um estoque para 18 anos de uso normal da droga. Além da cloroquina, existe outro medicamento, a ivermectina, que está sendo muito utilizado de maneira preventiva para a covid-19, mesmo que não exista nenhuma comprovação de eficácia. Na cidade de Itajaí, que tem 219.536 habitantes, o medicamento está sendo distribuído de maneira gratuita. No entanto, em pouco mais de um mês, o número de mortes e contágios duplicou. No dia 12 de junho, quando a cidade contava 17 óbitos por covid-19, foi iniciada a distribuição de doses do medicamento para 47 mil habitantes da cidade, a fim de que fossem utilizadas de forma preventiva. Inevitavelmente, dada a ineficácia bem reconhecida dessa medicação, Itajaí continua sendo uma das cidades mais atingidas pela pandemia em Santa Catarina, chegando hoje (8 de setembro de 2020) a 152 óbitos. O mesmo prefeito que considera importante distribuir uma droga sem qualquer efeito terapêutico ou preventivo alugou um contêiner frigorífico para ser usado como necrotério, instalado junto ao Centro Integrado de Saúde, que se ocupa de atender pacientes com covid-19. Essa medida responde à falta de espaço no necrotério da cidade.

Ao mesmo tempo que se adquirem e distribuem medicamentos sem eficácia, cloroquina e ivermectina, e que se difunde a suposta eficácia do ozônio, a ser aplicado por via retal, hospitais do estado impediram o ingresso de pacientes por falta de medicamentos. 
O Hospital Imperial de Caridade da cidade de Florianópolis (Simon, 5 ago. 2020), por exemplo, sofreu deficit importante nos estoques de medicamentos essenciais para lidar com a pandemia, particularmente sedativos e bloqueadores neuromusculares. Por esse motivo, no dia 18 de agosto o estado foi alvo de uma ação civil pública que exigia informações sobre os motivos que levaram ao incumprimento das medidas divulgadas pela assessoria técnica. Ainda que o Ministério Público tenha respondido a essa ação civil pública, afirmando que o plano de combate à pandemia apresentado pelo governo era adequado, os números de casos e mortos não deixam de aumentar.

Assim, podemos observar de que modo o negacionismo (Camargo Jr., Coeli, 2020), a divulgação de falsas informações e a exposição à morte se associam em uma necropolítica (Mbembe, 2018) que parece caracterizar a administração da pandemia no Brasil. A forma como a gestão da pandemia tem sido feita pelo presidente, por governadores e prefeitos se assemelha à lógica da necropolítica, mais preocupada em administrar a morte do que a vida. Não é por acaso que cada uma das medidas a ser implantadas, como circulação de transporte público, abertura de bares, academias etc., deixou de responder a informações epidemiológicas e sanitárias para se transformar em uma permanente roda de negociação com a câmara de empresários locais, em uma lógica neoliberal que privilegia a economia sobre a preservação de vidas. Uma lógica que inicialmente, e por pouco tempo, foi contestada e de alguma forma enfrentada pelo governo de Santa Catarina. Por fim, devemos destacar que essa necropolítica encontrou uma única barreira para sua expansão: a existência de um Sistema Único de Saúde (SUS) que possui uma estrutura sólida e com profissionais comprometidos, competentes e capacitados para enfrentar a epidemia.

\section{NOTA}

* Este texto é uma versão mais completa, atualizada e submetida a revisão por pares de um post publicado no blog de História, Ciências, Saúde - Manguinhos.

\section{REFERÊNCIAS}

BERLIVET, Luc; LOWY, Ilana. The problem with chloroquine. Epistemologists, methodologists, and the (mis) uses of medical history. História, Ciências, Saúde-Manguinhos, Section:

Coronavirus and History, 5 maio 2020.

Disponível em: http://www.revistahcsm. coc.fiocruz.br/english/the-problem-withchloroquine-epistemologists-methodologistsand-the-misuses-of-medical-history. Acesso em: 11 set. 2020 .

CAMARGO JR., Kenneth; COELI, Claudia Medina. A difícil tarefa de informar. Physis - Revista de Saúde Coletiva, v.30, n.2, p.1-5, 2020.

BISPO, Fábio; POTTER, Hyury. Coronavírus: SC aceita propostas forjadas e gasta $\mathrm{R} \$ 33$ milhões na compra de respiradores fantasmas. The
Intercept, 28 abr. 2020. Disponível em: https:// theintercept.com/2020/04/28/sc-propostaforjada-respiradores-fantasmas. Acesso em: 11 set. 2020.

GADOTTI, Fabio. Florianópolis vai ser destino seguro para turistas no verão, diz secretário municipal. ND+, 23 ago. 2020. Disponível em: https://ndmais.com.br/turismo/florianopolisvai-ser-destino-seguro-para-turistas-no-veraodiz-secretario-municipal. Acesso em: 11 set. 2020.

GOVERNO DO ESTADO DE SANTA CATARINA. Boletim Epidemiológico, COVID-19, 8 set. 2020.

GOVERNO DE SANTA CATARINA. Secretaria de Estado da Saúde. Nota Técnica n.001/2020 DIVE/LACEN/SES/SC. Dispõe sobre a notificação, 
investigação, coleta e orientações sobre os casos suspeitos da COVID-19 (SARS-CoV-2). Florianópolis: Secretaria de Estado de Saúde, 2020.

KOTSCHO, Ricardo. "Agora é guerra": Bolsonaro faz terrorismo e anuncia caos, saques, miséria. UOL, 14 maio 2020. Disponível em: https:// noticias.uol.com.br/colunas/balaio-dokotscho/2020/05/14/bolsonaro-faz-terrorismoe-anuncia-quebradeiras-caos-saques-miseria. htm. Acesso em: 11 set. 2020.

MBEMBE, Achille. Necropolítica. São Paulo: n-1 edições, 2018.
NOGUEIRA, André L. et al. Estimativa da subnotificação de casos da covid-19 no estado de Santa Catarina. Florianópolis: Universidade Federal de Santa Catarina, 2020. Disponível em: https://noticias.paginas.ufsc.br/files/2020/05/ aqui.pdf. Acesso em: 11 set. 2020.

SIMON, Guilherme. Hospital de Caridade em Florianópolis deixa de receber pacientes por falta de insumos. NSC Total, 5 ago. 2020. Disponível em: https://www.nsctotal.com.br/ noticias/hospital-de-caridade-em-florianopolisfecha-pronto-atendimento-por-falta-de-insum os?fbclid=IwAR0pQ2aAjixUS99C8TWZEjXUg gHe4FmTvnT5lAh4E7NNzGf46hRURQMioRw. Acesso em: 11 set. 2020.

\section{$\rightarrow \rightarrow \rightarrow<<<$}

